\title{
GCU
}

Glasgow Caledonian

University

University for the Common Good

\section{Scanning training for rehabilitation of visual field loss due to stroke: identifying and exploring training tools in use}

Hazelton, Christine; Pollock, Alex; Walsh, Glyn; Brady, Marian C.

Published in:

British Journal of Occupational Therapy

DOI:

$10.1177 / 0308022618809900$

Publication date:

2019

Document Version

Author accepted manuscript

Link to publication in ResearchOnline

Citation for published version (Harvard):

Hazelton, C, Pollock, A, Walsh, G \& Brady, MC 2019, 'Scanning training for rehabilitation of visual field loss due to stroke: identifying and exploring training tools in use', British Journal of Occupational Therapy, vol. 82, no. 8, pp. 502-511. https://doi.org/10.1177/0308022618809900

\section{General rights}

Copyright and moral rights for the publications made accessible in the public portal are retained by the authors and/or other copyright owners and it is a condition of accessing publications that users recognise and abide by the legal requirements associated with these rights.

Take down policy

If you believe that this document breaches copyright please view our takedown policy at https://edshare.gcu.ac.uk/id/eprint/5179 for details of how to contact us. 


\section{SCANNING TRAINING FOR REHABILITATION OF VISUAL FIELD LOSS DUE TO STROKE: IDENTIFYING AND EXPLORING TRAINING TOOLS IN USE}

Short Title: Identifying and describing scanning training tools for visual field loss

\section{Author List:}

1. Christine Hazelton, Research Fellow, Nursing, Midwifery and Allied Health Professions (NMAHP) Research Unit, Glasgow Caledonian University, UK.

2. Alex Pollock, Senior Research Fellow, NMAHP Research Unit, Glasgow Caledonian University, UK.

3. Glyn Walsh, Senior Lecturer (retired), School of Health and Life Sciences, Glasgow Caledonian University, UK.

4. Marian C. Brady, Professor, NMAHP Research Unit, Glasgow Caledonian University, UK.

\section{Corresponding Author:}

Christine Hazelton, Nursing, Midwifery and Allied Health Professions (NMAHP) Research Unit, A600 Govan Mbeki Building, Glasgow Caledonian University, Cowcaddens Road, Glasgow. G4 OBA

christine.hazelton@gcu.ac.uk 


\section{ABSTRACT}

\section{Introduction}

Visual field loss affects one fifth of stroke survivors, limiting daily activities and reducing quality of life. Scanning training is a commonly used intervention, but there is variation in how this is delivered. This study aimed to identify the scanning training tools used in Scotland and describe their training parameters, delivery and suitability for use with stroke survivors.

\section{Methods}

An email survey identified scanning training tools used in Scotland.

Two Expert Panel meetings gained consensus on the motor, language and cognitive skills required to use each scanning training tool. Video capture techniques gathered objective measures of training parameters.

\section{Results}

Ten scanning training tools were identified.

These tools used four delivery methods: paper-based, computer software, web-based and specialised equipment. They aimed to improve reading, perception or general visual skills. Fast, saccadic eye movements were most frequently targeted: two interventions also encouraged head movements. Session duration, frequency, and therapist support varied considerably. The level of motor, language, and cognitive skills required for each tool was determined.

\section{Conclusion}

Scanning training tools used in Scotland vary in delivery modality, functional abilities required for use and visual skills trained. This information will support clinical decision-making and inform future research on training effectiveness and feasibility.

Keywords: Stroke, visual field loss, homonymous hemianopia, rehabilitation, compensation, scanning training 


\section{INTRODUCTION}

Visual field loss (VFL) affects one fifth of stroke survivors, around 240,000 people in the UK (Ali et al., 2013). It is due to damage to the visual pathways that carry information from the eyes to the primary visual processing centres in the occiput. VFL typically affects one entire half of the field on the same side in both eyes, effectively making the person blind to one side of space. The impact of the loss of visual information is compounded by subsequent eye movement changes, as these smaller, repetitive movements increase the time taken to view an entire scene (Zihl, 1999).

The impact of VFL on daily life has been clearly established. Stroke survivors with VFL struggle to interact with their environment, and report difficulties with mobility and navigation, leading to falls and unwillingness to leave the home (Hazelton et al., 2015). Key activity of daily living (ADL) difficulties are in grooming and feeding, as well as driving, shopping and financial management (Warren, 2009). Psychological consequences are wide-ranging, centring on fear and reduced selfconfidence (Hazelton et al., 2015; Rowe, 2017). Overall there is poorer functional outcome (Ali et al., 2013), poorer vision-related quality of life (Chen et al., 2009), reduced engagement in rehabilitation contributing to poor stroke recovery and increased chance of institutionalisation (Jones and Shinton, 2006). With improving stroke survival rates (Feigin et al., 2009), increasing numbers of survivors are living with the long-term consequences of their VFL.

Finding effective treatments for visual loss is a top research priority for stroke survivors, their carers and clinicians in Scotland (Pollock et al., 2012). To date, there is not enough high-quality evidence to state if any treatment approach is effective (Pollock et al., 2011). The impact of this lack of research evidence on UK clinical practice is clear: guidelines give little direction in managing VFL (Royal College of Physicians, 2016); clinicians state that lack of evidence, along with limited training and protocols are barriers to improving services (Pollock, Hazelton and Brady, 2011) and there is huge variation in care (Rowe, 2014). Stroke survivors therefore may not be receiving the most appropriate management for their VFL, and may not achieve optimal rehabilitation outcomes, in visual function, ADL ability and quality of life.

Current occupational therapy for stroke survivors with VFL often involves scanning training (Pollock, Hazelton and Brady, 2011). Scanning training (also called visual search or eye movement training) aims to teach more efficient, effective eye (and head) movements toward the side of VFL. Although there is a lack of conclusive evidence of effectiveness of scanning training, it is a promising technique (Pollock et al., 2011). Occupational Therapists typically teach broad, horizontal scanning movements during practice of relevant ADLs (Turton, 2014). Scanning training may also be administered using devices or tools, including computer-based or paper-based exercises (Pollock, Hazelton and Brady, 2011). These tools require less therapist support, so provide opportunities to increase the dose of training delivered despite limited resources and personnel. The specific tools used by Occupational Therapists as part of routine clinical practice have not previously been identified or described. Detailed description of the components of an intervention forms the first stage of "unpacking the black box" (Pomeroy et al., 2001) of how rehabilitation works. It is an essential stage in testing the feasibility and effectiveness of an intervention. Crucially clear description of the components of an intervention also informs clinical practice: detailed description would support Occupational Therapists to choose the scanning training tools suitable for their care setting and appropriate to the 
needs and abilities of individual stroke survivors. Identification and description of components of currently used scanning training tools is therefore important to support clinical decision making and inform future research.

\section{AIM}

The aim of this study was to identify the scanning training tools used in Scotland for rehabilitation of VFL in stroke survivors, and fully describe the main components of each.

\section{Methods}

A two-stage method was used, involving identification of scanning training tools (Phase 1 ) and description of these tools (Phase 2). University ethical approval was obtained.

\section{Identification of Interventions: Email Survey}

The clinicians who use scanning training come from a range of vision and stroke professions (e.g. Low Vision Rehabilitation Officers, Occupational Therapists) and varied care settings, employers and geographic locations. No clear listing of the relevant clinicians existed. We used a snowball sampling method, which uses referrals from first participants to identify others, to reach this "hidden population" (Magnani et al., 2005).

An email survey was developed using guidelines to maximise response rates (Edwards et al., 2009) and piloted with a stroke rehabilitation research group (supplementary material 1). It asked the recipient to (i) provide details of the scanning training tools used for rehabilitation of stroke-related VFL in Scotland (ii) to forward the email on to any appropriate contacts. The email contained clear information about the anonymisation, use and storage of survey data: completing and returning the survey was taken to imply consent had been given.

An initial sample of groups known to the research team (from previous projects and events) to have knowledge of scanning training for VFL was identified (supplementary material 2). The survey was emailed to members of these groups, a reminder sent four weeks later, and overall time limit of eight weeks set for responses.

Pre-defined inclusion criteria were applied to all responses to identify relevant interventions. The criteria were that interventions (i) encouraged or trained eye movements, (ii) were not limited to ward use (iii) were available in Scotland and (iv) involved a training tool or device (not just verbal instructions or practiced only in ADL tasks). A final list of scanning training tools in use in Scotland was compiled.

\section{Describing key components: two-stage mixed methods data collection}

\section{I Developing a list of key components to be described}


There is limited research into scanning training interventions, and poor reporting within published studies (Pollock et al., 2011). Thus, there was no comprehensive information about which intervention components are important to delivering effective and feasible therapy. We used an iterative process to develop a list of potentially important scanning training components.

An initial list of potentially important components was developed from the published papers on scanning training interventions (Pollock et al., 2011), supplemented with evidence of key components in stroke and low vision interventions (Glässel et al., 2012; Phillip and Zhao, 1983; Schmidt and Wrisberg, 2007; Wade and Swanston, 1991). Three consultative rounds, involving around 25 individuals (NHS clinicians working in stroke rehabilitation; vision care researchers and professionals; and stroke rehabilitation researchers), led to additions, refinements and clarifications. A final list of key components to be described was agreed, grouped into categories: (i) how the intervention is used - the practical details of use, including access information, cost, delivery method and dosage (ii) what it trains - the optical and visual characteristics of training (iii) who can use it the functional skills needed by a stroke survivor to use the tool (in motor, language, sensory and cognitive domains).

\section{$\underline{2.2}$ Gathering data on key intervention components}

The following methods were used to gather the data required to describe the listed components for each scanning training tool.

(a) Literature Consultation: All user documentation (manuals, user guides) was obtained for each tool. Google and Google Scholar were searched (using the intervention name) for associated research and developers contacted for further information. We extracted descriptions of where to access interventions, their cost, how to use the tool and recommended training schedules.

(b) Observation: Each tool was set-up as specified in the user documentation and the range of exercises available was examined. The researcher observed and judged the components of interest, including the process of setting up and accessing training, exercise difficulty and types of feedback.

(c) Image Capture and Analysis: To objectively gather precise data on the physical dimensions of the training exercises, an image capture and analysis method was used. A summary of this method is given below, for more detailed description see supplementary material 3, which includes the experiments used to systematically confirm the method's accuracy and precision.

Images of the easiest exercises in each intervention were captured using a tripod-mounted Samsung $H M X$ f80SN HD camera, at $150 \mathrm{~cm}$. A small plastic rectangle (reference card) of known size was included in recordings. Images were imported into Photoshop (from Adobe Master Collection CS5), and using the measurement features the onscreen pixel count for all dimensions of interest, as well as the reference card were recorded. Calculating a mm-to-pixel value for the reference card, and using the pixel measurement for each intervention, the actual dimensions in $\mathrm{mm}$ were calculated.

(d) Expert Panel assessment: The functional abilities required to use each intervention were assessed at expert panels meetings. This process took a task analysis approach, used in Occupational Therapy to understand the physical, cognitive and other functional abilities that an 
activity involves, and as applied in Optometry to determine the skill level in each ability that are required for a person to engage in that activity (North, 2001).

Two expert panel meetings were held, with clinical specialist participants purposively selected to match the functional abilities to be judged (Table 1).

\section{Table 1 here}

At each meeting the scanning training tools were demonstrated. Attendees were given a list of functional abilities (motor, sensory, language and cognitive) and asked to firstly state whether a specific ability was required to use that tool, and if so, to secondly grade the level of skill required. The levels was graded as low, medium or high (Watson, 1997), and experts instructed to think of them on a scale divided equally in three, running from no skill required at the lowest end, to the skill level seen in a typical non-stroke population at the highest end. The grading levels for all skills were determined by discussion by the experts, which continued until consensus was reached. Discussion was facilitated throughout by the researcher, encouraging all members to take part, and ensuring a clear agreement was reached for all issues (Slocum, 2003). Participants in meeting 1 also considered the type of eye movements the interventions were training, primarily determining if these were pursuit or saccadic eye movements. This method was piloted before use with a stroke Nurse and stroke Occupational Therapist.

\section{RESULTS}

\section{Identification of interventions}

A total of 86 email surveys were sent. Twenty responses were received, 13 from those emailed directly and seven from the wider snowballing process. The professional backgrounds of responders included Low Vision Rehabilitation Officers $(n=5)$, Orthoptists $(n=5)$, Physiotherapists $(n=3)$, Occupational Therapists ( $n=2)$, Low Vision Service Managers ( $n=2)$, Nurse (1), Ophthalmologist (1) and Researcher (1). 21 interventions were identified, of which ten met our inclusion criteria for scanning training tools (Table 2, column 1). Each of these tools was identified by just one respondent, except for NVT (Neuro Vision Technology) Scanning Training device, which was identified by eight separate clinicians.

\section{Description of intervention components}

Intervention assessment forms were completed for all ten tools, with consensus reached on all grading levels in the expert panel meetings. User manuals or guides were available for all but one scanning training tool (Eye Track). Research literature was identified relating to three tools: ReadRight (Ong et al., 2012; Spitzyna et al., 2007), NVT scanning device (Gouvier et al., 1984; Hayes et al., 2012; Webster et al., 1984) and VISIOcoach (Roth et al., 2009).

Brief descriptions of each of the 10 tools is provided in Table 2. Four different modes of training delivery were identified, and these have been used to group the interventions in subsequent tables, to aid comparison within and between these groups.

Table 2 here 
The key scanning training tool components relating to (i) how it is used and the specifics of (ii) what does it train are described in Table 3.

\section{Table 3 here}

The process of tabulation identified areas of similarity and difference in the components of scanning training tools. The most fundamental difference was delivery modality, with paper-based, specialist, and both online and standalone computer tools. The study's inclusion criteria meant all ten identified tools, with their different modality-specific equipment requirements, were amendable for use in community rehabilitation settings. All but two tools (two NVT interventions) were available for use by therapists without further training. However, the costs of providing these tools varied, from free (Rainbow Readers, Read-Right) to $\mathrm{f} 4374$ for the specialist Biometrics E-Link.

Once provided, most scanning training tools $(n=7)$ could be used with low levels of professional support: four required therapist assistance to begin training (NVT pen and paper, Rainbow Readers, Eye Track, Lexion) and three were fully self-directed (MyHappyNeuron, Read-Right, VISIOcoach). All three self-directed tools were computer-based and designed for direct access (or purchase) and use by stroke survivors themselves. The length, frequency and duration of scanning training was not always stated $(n=4)$ : in these cases, documentation suggested these parameters be chosen by the therapist, and tailored to an individual's needs. When stated, session duration varied from 5 minutes to 1 hour per day, although for the latter this was for a limited period of 6 weeks.

Greater similarity was noted in the type of eye movements addressed by the scanning training tools. All were considered to encourage saccadic eye movements, the fast movements used to change fixation. For Read-Right, the smaller micro-saccades, associated with the left-to-right reading eyemovements were specified. Biometrics E-Link and Read-Right also encouraging pursuits, the slower movements used to follow a moving target. The area of visual field stimulated was the central $38^{\circ}$ in all but one of the tools. However, the use of scanning head movements was less clear, being noted for only four interventions: two expressly encouraged head movements in order to view the entire breadth of a visual scene (NVT scanning training tools) with two others advising limiting head movements, as they aimed to improve eye movements alone (Rainbow Readers, VISIOcoach). Of note were the three different underlying training aims of these tools - to improve reading (NVT pen and paper, Rainbow Readers, Read-Right), visual perceptual skills (Brainwave-R Visual Processing, MyHappyNeuron, Eye Track) or general visual skills and mobility (NVT Scanning Device, VISIOcoach). Additionally, only four interventions were designed specifically to address VFL.

Table 4 shows (iii) who can use it, as indicated by the level of functional skills required to engage with each scanning training tool, agreed by the expert panellists.

\section{Table 4 here}

None of the tools were judged to require motor ability in the lower limbs, or mobility. Sitting balance and head, neck and trunk control were required to varying degrees for all ten tools, with higher levels of upper limb skill required for interventions with pencil or mouse-based interaction (Brainwave R visual processing, Rainbow Readers, Biometrics, MyHappyNeuron, Eye Track, Lexion, VISIOcoach). Across the tools, generally low language and cognitive skills were required. However the more complex computer interventions MyHappyNeuron, Read-Right and VISIOcoach required 
high-level reading ability, with MyHappyNeuron also requiring good cognition, in order to understand the instructions or perform the training exercises.

\section{DISCUSSION}

\section{Summary of key findings}

Ten different scanning training tools were identified as being used in Scotland for the rehabilitation of stroke-related VFL. This study has systematically described key components likely to impact on scanning training feasibility and effect, to begin unpacking the black box of how these interventions work and to inform clinical practice. All tools focused on training saccadic eye movements, usually within the central $38^{\circ}$, and all required good function in the upper body and upper limb motor skills. However, there were also clear differences between groups of tools, including in the mode of delivery and practicalities of their use.

There is limited evidence on the rehabilitation interventions used for stroke-related visual problems (Pollock, Hazelton and Brady, 2011; Rowe, 2014). A number of studies have explored the effectiveness of scanning training, or relative effects of different types of scanning training (see systematic reviews by de Haan (2014), Hanna (2017) and Pollock (2011). When compared to other rehabilitation approaches, including prisms (Rowe et al., 2016) and restorative training (Modden et al., 2012), scanning training has appeared a more effective rehabilitation approach. However, in this study a minority of scanning training interventions (3/10) had supporting research, and only four were designed expressly for improving eye movements in people with stroke-related VFL. These findings suggest that clinicians are using sources other than research to inform their choice of tool, such as clinical reasoning, personal experience and practical considerations (Chen and Bode, 2011). This study provides detailed descriptions of the tools used to deliver scanning training in Scotland. The results highlight diversity across the tool components described, notably in the modality of delivery, focus of training, use of head movements, language and cognitive skills required, access costs, level of support required and therapy dosage and schedule. These variations potentially impact on intervention's feasibility and effectiveness and clearly have implications for the selection of interventions for use in clinical practice and for research evaluation of these tools.

\section{Limitations}

Several limitations of this study must be noted. The snowball methodology, used to identify scanning training tools, can introduce bias, as the initial participants are based on the researcher's contacts (Magnani et al., 2005). In this case seven referred responses were generated, and as a result it is possible that some scanning training tools were not identified. However, the very heterogeneous nature of the clinical population of interest meant this method was most likely to prove successful. It is also likely that the tools available will change over time: since the initial identification process we have become aware of three further scanning training tools in use in Scotland (DREX, Eye-Search, NeuroEyeCoach; Table 5). This resource will need to be updated regularly to provide accurate, comprehensive information. The intervention components chosen for investigation were based on relevant literature and the opinion of experienced stroke researchers and clinicians. It is possible that some relevant components were omitted, but the wide consultation process aimed to minimise this possibility. One of the description methods required 
judgement from the expert panel members, which may have been influenced by the expertise of those present, with the potential for dominant personalities to sway results (Patton, 2002). However such bias would have been minimised through the inclusion of a variety of clinical viewpoints, the use of group discussion and always gaining consensus of the grading levels (Slocum, 2003).

Table 5 here

\section{Clinical Implications}

The detailed information compiled by this study clearly has implications for the selection of interventions for use in clinical practice. For professionals providing scanning training, the study results firstly identify a range of scanning training tools available, that they may wish to incorporate into practice. Given that most (9/10) tools were identified by only one survey responder (suggesting clinicians typically use only one specific tool) this will likely provide new information to many clinicians. Although the study was conducted in Scotland, many of these tools are available to purchase or accessible online (Table 3), so findings are applicable in the UK and internationally.

Secondly, the detailed descriptions provide information that clinicians can use to inform their choice of tools. This data can be used to help decide which tool (i) meets a patient's visual rehabilitation needs (ii) a patient can use and (iii) is practically deliverable in a specific care setting. To determine how to (i) meet a patient's rehabilitation needs, the clinician should consider the most appropriate training aim (reading/visual perception/general visual skills and mobility), eye movements to be encouraged (saccades/pursuits) and whether the use of head movements is needed to address their visual needs and use Table 3 to determine which tool best corresponds to these needs. To determine which tool (ii) a patient can use, the clinician could consider the stroke survivor's abilities in specific motor, language and cognitive skills (low/medium/high) and use Table 4 to identify which tools are accessible for that individual. To determine which tool (iii) is most practically deliverable in a specific care setting the cost of interventions, professional support required (supported throughout/self-directed with initial support/ self-directed throughout) and dosage requirements must be considered within the local service and budgeting context, then use Table 3 to find the most suitable tool. Clinicians can also use the website and email access information to obtain further information about any tool of interest. Given the current lack of guidelines on how to provide scanning training for VFL (Pollock, Hazelton and Brady, 2011), this decision-making method, combined with expert clinical judgement, should enable the choice of rehabilitation tools that are appropriate for each individual stroke survivor, a key principle of both stroke (Royal College of Physicians, 2016) and vision (Royal National Institute of Blind People, 2016) rehabilitation.

\section{Research Implications}

The detailed intervention descriptions also enable researchers to begin unpacking the black box of scanning training tools. We have identified variations in many of the described components: by testing the impact of these variations, future studies can explore the role it plays in scanning training effectiveness and feasibility. We found a number of differences between scanning training tools: comparative studies may be most useful in helping elucidate any differences in the mechanisms of 
action, key to developing more effective tools (Craig et al., 2008). In order to aid research into these mechanisms, we recommend full description of scanning training interventions, covering the components identified here and using guidelines such as TIDieR (Hoffmann et al., 2014), be included in future studies.

\section{CONCLUSION}

A range of scanning training tools are available for the rehabilitation of stroke survivors with VFL. Identifying the specific tools available and describing their components can inform and improve clinical practice, by enabling healthcare professionals to choose interventions most suitable to individual patient needs, abilities and care setting.

\section{KEY FINDINGS}

- A range of scanning training tools are available for stroke survivors with VFL

- These tools vary in their delivery methods, support required, and eye movements trained

\section{WHAT THE STUDY HAS ADDED}

This study provides a comprehensive description of scanning training tools for VFL used in Scotland. It supports Occupational Therapists to choose the most suitable tool for each stroke survivor, to maximise their rehabilitation outcome.

Acknowledgements: we would like to thank the designers of all included scanning training tools for providing free access during this study. We wish to note that MyHappyNeuron is designed for a general population, and a version specifically for healthcare use (HappyNeuron Pro) is also available.

\section{STATEMENTS}

Research Ethics: approval was obtained from the School of Health and Life Sciences, Glasgow Caledonian University (2012).

Consent: no stroke survivor participants were involved in this study. All professionals taking part in the Expert Panel Assessments provided verbal consent to take part and for written notes of the decision-making process and final agreements to be recorded.

Declaration of Conflicting Interests: The authors declared no potential conflicts of interest with respect to the research, authorship and/or publication of this article.

Funding: the authors disclosed receipt of the following financial support for the research, authorship and/or publication of this article: This study was funded by The Stroke Association (UK) via a Junior Research and Training Fellowship held by the lead author (TSA JRTF 2011/02). MB, AP and the 
NMAHP Research Unit are funded by the Scottish Government Health and Social Care Directorates. The views expressed here are those of the authors and not necessarily those of the funders.

Contributorship: All authors contributed to designing the study methodology: this included the survey content and layout in phase 1 , and content and specific methods in the intervention analysis in phase 2. Christine Hazelton disseminated and collected all returned surveys, conducted all of the research activities in phase 2 , conducted primary data analyses and prepared the first draft of this manuscript. All authors were involved in interpreting phase 1 and 2 data, reviewed and edited the manuscript and approved the final version.

\section{REFERENCE LIST}

Ali M, Hazelton C, Lyden P, et al. (2013) Recovery From Poststroke Visual Impairment: Evidence From a Clinical Trials Resource. Neurorehabilitation and Neural Repair 27(2): 133-141.

Chen C and Bode R (2011) Factors influencing therapists' decision-making in the acceptance of new technology devices in stroke rehabilitation. American Journal of Physical Medicine and Rehabilitation 90(5): 415-425.

Chen CS, Lee AW, Clarke G, et al. (2009) Vision-Related Quality of Life in Patients with Complete Homonymous Hemianopia Post Stroke. Topics in Stroke Rehabilitation 16(6): 445-453.

Craig P, Dieppe P, Macintyre S, et al. (2008) Developing and evaluating complex interventions: new guidance. London: Medical Research Council.

De Haan GA, Heutink J, Melis-Dankers BJM, et al. (2014) Spontaneous recovery and treatment effects in patients with homonymous visual field defects : a meta-analysis of existing literature in terms of the ICF framework. Survey of Ophthalmology 59(1): 77-96.

Edwards PJ, Roberts I, Clarke MJ, et al. (2009) Methods to increase response to postal and electronic questionnaires. Cochrane Database of Systematic Reviews (Issue 3): Art. No.: MR000008. DOI: 10.1002/14651858.MR000008.pub4.

Feigin VL, Lawes CM, Bennett DA, et al. (2009) Worldwide stroke incidence and early case fatality reported in 56 population-based studies: a systematic review. The Lancet Neurology 8(4): 355369.

Glässel A, Coenen M, Kollerits B, et al. (2012) Validation of the extended ICF core set for stroke from the patient perspective using focus groups. Disability and rehabilitation 34(2): 157-166.

Gouvier WD, Cottam G, Beissel GF, et al. (1984) Behavioral Interventions with Stroke Patients for Improving Wheelchair Navigation. The International Journal of Clinical Neuropsychology 6(3): 186-190.

Hanna KL, Hepworth LR and Rowe FJ (2017) The treatment methods for post-stroke visual impairment: A systematic review. Brain and Behavior 7(5): e00682. 
Hayes A, Chen CS, Clarke G, et al. (2012) Functional improvements following the use of the NVT Vision Rehabilitation program for patients with hemianopia following stroke. NeuroRehabilitation 31(1): 19-30.

Hazelton C, Pollock A, Taylor A, et al. (2015) Visual field loss after stroke: exploring the impact on daily life. Clinical Rehabilitation 29(10): 1016.

Hoffmann T, Glasziou P, Boutron I, et al. (2014) Better reporting of interventions: template for intervention description and replication (TIDieR) checklist and guide. British Medical Journal 7: (348): g1687.

Jones SA and Shinton RA (2006) Improving outcome in stroke patients with visual problems. Age and Aging 35(6): 560-565.

Magnani R, Sabin K, Saidel T, et al. (2005) Review of sampling hard-to-reach and hidden populations for HIV surveillance. AIDS 19(S2): 67-72.

Modden C, Behrens M, Damke I, et al. (2012) A Randomized Controlled Trial Comparing 2 Interventions for Visual Field Loss With Standard Occupational Therapy During Inpatient Stroke Rehabilitation. Neurorehabilitation and Neural Repair 26(5): 463-469. DOI: $10.1177 / 1545968311425927$.

North R (2001) Work and the eye. 2nd ed. Oxford: Butterworth-Heinemann.

Ong Y-H, Brown MM, Robinson P, et al. (2012) Read-Right: a 'web app' that improves reading speeds in patients with hemianopia. Journal of Neurology 259(12): 2611-5.

Patton MQ (2002) Qualitative Research \& Evaluation Methods. 3rd ed. Saint Paul, MN: Sage Publications Ltd.

Phillip B and Zhao H (1983) Predictors of Assistive Technology Abandonment. Assistive Technology 5(1): 36-43.

Pollock A, Hazelton C, Henderson C, et al. (2011) Interventions for visual field defects in patients with stroke. Cochrane Database of Systematic Reviews (10): Art. No.: CD008388. DOI: 10.1002/14651858.CD008388.pub2..

Pollock A, Hazelton C and Brady M (2011) Visual problems after stroke: a survey of current practice in UK stroke inpatient settings. Topic in Stroke Rehabilitation 18(5): 643-651.

Pollock A, George BS, Fenton M, et al. (2012) Top ten research priorities relating to life after stroke. The Lancet Neurology 11(3): 209.

Pomeroy VM, Niven DS, Barrow S, et al. (2001) Unpacking the black box of nursing and therapy practice for post-stroke shoulder pain: a precursor to evaluation. Clinical rehabilitation 15(1): 67-83.

Roth T, Sokolov AN, Messias A, et al. (2009) Comparing explorative saccade and flicker training in hemianopia: a randomized controlled study. Neurology 72(4): 324-31. 
Rowe F (2017) Stroke survivors' views and experiences on impact of visual impairment. Brain and Behavior 7(9): e00778.

Rowe FJ (2014) Care provision and unmet need for post stroke visual impairment. London: Thomas Pocklington Trust.

Rowe FJ, Conroy EJ, Bedson E, et al. (2016) A pilot randomized controlled trial comparing effectiveness of prism glasses, visual search training and standard care in hemianopia. Acta Neurologica Scandinavica 136 (4): 310-321. DOI: 10.1111/ane.12725.

Royal College of Physicians (2016) National Clinical Guidelines for Stroke - Fifth Edition. London: RCP.

Royal National Institute of Blind People (2016) 10 Principles of Good Practice in Vision Rehabilitation. London: RNIB.

Schmidt R and Wrisberg C (2007) Motor Learning and Performance. 4th ed. Illinois, USA.

Slocum N (2003) Participatory Methods Toolkit. A practitioner's manual. Brussels: United Nations.

Spitzyna GA, Wise RJS, McDonald SA, et al. (2007) Optokinetic therapy improves text reading in patients with hemianopic alexia: a controlled trial. Neurology 68(22): 1922-30.

Turton A (2014) Description and measurement of visual scanning training in Occupational Therapy for patients with visual search deficits following stroke. London: College of Occupational Therapists.

Wade NJ and Swanston M (1991) Visual Perception: An Introduction. Guildford: Routledge.

Warren M (2009) Pilot Study on Activities of Daily Living Limitations in Adults With Hemianopsia. American Journal of Occupational Therapy 63(5): 626-633.

Watson DE (1997) Task Analysis: An Occupational Performance Approach. Bethesda, MA: The American Occupational Association Inc.

Webster JS, Jones S, Blanton P, et al. (1984) Visual Scanning Training With Stroke Patients. Behavior Therapy 15(2): 129-143.

Zihl J (1999) Oculomotor scanning performance in subjects with homonymous visual field disorders. Visual Impairment Research 1(1): 23-31. 


\section{FIGURES AND TABLES}

Table 1. Expert Panel Meetings: focus and attendee expertise

\begin{tabular}{|c|c|c|}
\hline $\begin{array}{l}\text { Meeting } \\
\text { Number }\end{array}$ & Focus & Attendees \\
\hline 1 & $\begin{array}{l}\text { Visual and cognitive } \\
\text { functions }\end{array}$ & $\begin{array}{l}\text { - Orthoptist } \\
\text { - two stroke-specialist Occupational Therapists } \\
\text { (with interest or research background in visual and } \\
\text { cognitive impairment) } \\
\text { - Psychologist (with expertise in stroke and eye } \\
\text { movement research) }\end{array}$ \\
\hline 2 & $\begin{array}{l}\text { Motor, sensory and } \\
\text { language functions }\end{array}$ & $\begin{array}{l}\text { - } \text { two stroke specialist Physiotherapists } \\
\text { - } \quad \text { two stroke specialist Speech and Language Therapists } \\
\text { - } \quad \text { stroke specialist Occupational Therapist } \\
\text { - } \quad \text { stroke specialist Nurse }\end{array}$ \\
\hline
\end{tabular}


Table 2. Identified scanning training tools: brief descriptions

\begin{tabular}{|c|c|c|}
\hline Scanning Training Tools & Modality & Brief Description \\
\hline Brainwave-R workbook & Paper-based & $\begin{array}{l}\text { An A4 exercise book divided into the clinician's instructions and answers, and user's exercises. Initial } \\
\text { exercises require eye movements to scan from letters on one side of the page to the other. They quickly } \\
\text { progress to much more difficult exercises that involve higher visual processing skills and cognitive } \\
\text { abilities. The therapist provides instruction, encouragement, and feedback on progress. }\end{array}$ \\
\hline Eye Track training software & $\begin{array}{l}\text { Computer } \\
\text { program }\end{array}$ & $\begin{array}{l}\text { This intervention uses the search for a criminal called Ronnie Retina as the background to the activities. } \\
\text { There are four games, each highly coloured and interactive, with responses provided using a mouse: } \\
\text { words, tones and visual cues are used to indicate right and wrong answers. There are five difficulty levels } \\
\text { for each game, and the level can be set before beginning. The programme also allows worksheets to be } \\
\text { printed off. }\end{array}$ \\
\hline Lexion software & $\begin{array}{l}\text { Computer } \\
\text { program }\end{array}$ & $\begin{array}{l}\text { Lexion (version 4) software, loaded to a computer from a disc, provides a large range and number of } \\
\text { language and word-based exercises. Exercises are designed for children, and use relatively short, simple, } \\
\text { picture or word-based activities. Each user can have a customised set of exercises, with tailored difficulty } \\
\text { levels, set up for them to perform at home. }\end{array}$ \\
\hline NVT scanning device & Specialist & $\begin{array}{l}\text { This specialist equipment consists of a "lightbox" around } 1.5 \mathrm{~m} \text { wide. It is made up of } 2 \text { rows of equally } \\
\text { spaced, coloured lights, used to assess and then train the visual field. The light box is the first "static" }\end{array}$ \\
\hline
\end{tabular}




\begin{tabular}{|c|c|c|}
\hline training & equipment & $\begin{array}{l}\text { stage in a larger rehabilitation programme for VFL that moves on to "dynamic" training in real life } \\
\text { environments and tasks. It is used to train the systematic use of a broad horizontal eye and head } \\
\text { movement, typically from unseen to seen visual field. }\end{array}$ \\
\hline $\begin{array}{l}\text { NVT pen and paper } \\
\text { exercises }\end{array}$ & Paper-based & $\begin{array}{l}\text { Landscape-oriented A4 sheets consisting mostly of rows of letters, words and numbers, as well as } \\
\text { cancellation-type symbol tasks and more complex figures. In most tasks the user is asked to scan from } \\
\text { left to right and point to or count the number of times a particular target occurs }\end{array}$ \\
\hline Rainbow Readers & Paper-based & $\begin{array}{l}\text { Rainbow Readers consists primarily of a booklet of exercises, made up of simple symbols arranged in } \\
\text { broken lines across the page. The aim is to search for, and circle, a specific symbol within a line of varied } \\
\text { other symbols. Exercises increase in difficulty through the booklet. Support is required throughout to } \\
\text { point out any mistakes, and this can be provided by a carer. }\end{array}$ \\
\hline Read-Right online training & Online & $\begin{array}{l}\text { Online text-based eye-movement training consisting of text from books (from Harry Potter to } \\
\text { philosophical works) or online news pages. Text is presented in one row, continually moving leftwards, } \\
\text { which the user is simply required to read. The word speed and colour can be changed. }\end{array}$ \\
\hline VISIOcoach & $\begin{array}{l}\text { Computer } \\
\text { program }\end{array}$ & $\begin{array}{l}\text { The training is provided by a computer program installed from a USB drive. The point of each exercise is } \\
\text { to find the number indicated at the start using eye movements (not head movements) and mark with a } \\
\text { mouse. The target number is hidden in an irregular pattern of numbers on a white background. There are } \\
\text { three difficulty levels: in each session a user should stay at the same level, and progress to a higher level } \\
\text { at the next session. }\end{array}$ \\
\hline
\end{tabular}


Table 3. Scanning training interventions: how is it used and what does it train?

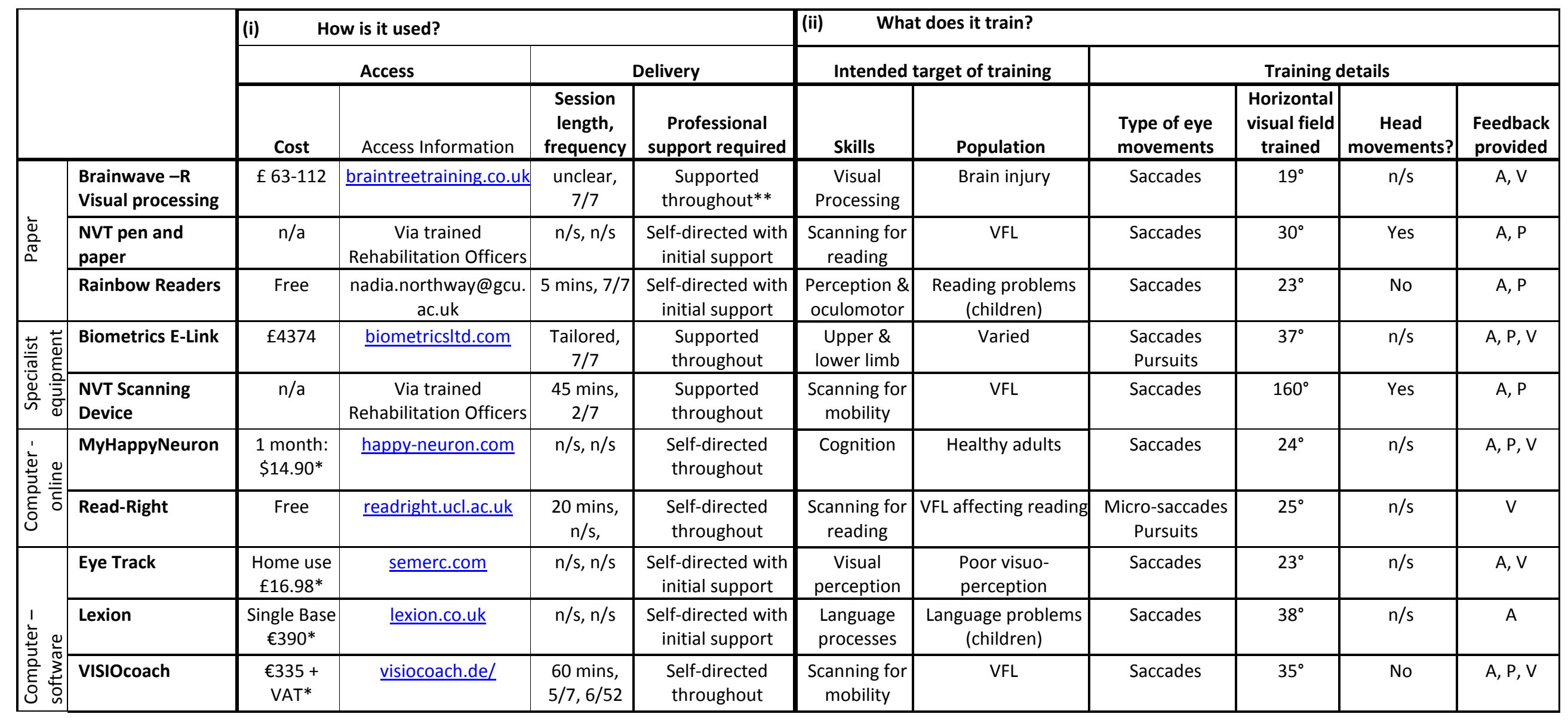

Key:

Session frequency: $x / 7=$ number of days per week, $x / 52=$ number of weeks, $n / s=$ not stated

Feedback: $\mathrm{A}=$ audio, $\mathrm{P}=$ proprioceptive, $\mathrm{V}=\mathrm{visual}$

* other price options are available **the booklet notes that any interested clinician, carer or friend can fulfil the "therapist" role to support the user 
Table 4. Scanning training tools: who can use it? The ability levels in key motor, language and cognitive skills required to engage with the intervention

\begin{tabular}{|c|c|c|c|c|c|c|c|c|c|c|}
\hline & & \multicolumn{4}{|c|}{ Motor skills } & \multicolumn{3}{|c|}{ Language skills } & \multicolumn{2}{|c|}{ Cognitive skills } \\
\hline & & $\begin{array}{l}\text { Sitting } \\
\text { Balance }\end{array}$ & $\begin{array}{l}\text { Head, Neck } \\
\text { \& Trunk }\end{array}$ & Upper Limb & $\begin{array}{l}\text { Rise to } \\
\text { stand, } \\
\text { stand, walk }\end{array}$ & $\begin{array}{l}\text { Understand } \\
\text { speech }\end{array}$ & Reading & Speaking & Attention & Memory \\
\hline \multirow[b]{3}{*}{$\begin{array}{l}\bar{d} \\
\stackrel{2}{\pi} \\
\check{\alpha}\end{array}$} & $\begin{array}{l}\text { Brainwave -R Visual } \\
\text { processing }\end{array}$ & L & M & $\mathrm{H}$ & - & $M$ & - & L-M & M & L \\
\hline & NVT pen and paper & $M$ & $\mathrm{H}$ & - & - & $\mathrm{L}$ & L & $\mathrm{L}$ & $M$ & $\mathrm{~L}$ \\
\hline & Rainbow Readers & L & $\mathrm{H}$ & $\mathrm{H}$ & - & $\mathrm{L}$ & - & $M$ & M & L \\
\hline \multirow{2}{*}{ 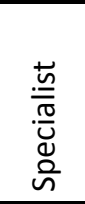 } & Biometrics E-Link & $M$ & $\mathrm{M}-\mathrm{H}$ & $\mathrm{H}$ & - & $L$ & - & - & $M$ & $\mathrm{~L}$ \\
\hline & NVT Scanning Device & $\mathrm{M}-\mathrm{H}$ & $\mathrm{H}$ & - & - & M & - & - & $\mathrm{L}$ & $\mathrm{L}$ \\
\hline \multirow{2}{*}{ 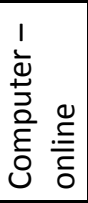 } & MyHappyNeuron & $M$ & $\mathrm{H}$ & $\mathrm{H}$ & - & - & $\mathrm{H}$ & - & $\mathrm{H}$ & $\mathrm{H}$ \\
\hline & Read-Right & $L$ & $M$ & - & - & - & $\mathrm{H}$ & - & $\mathrm{H}$ & $M$ \\
\hline \multirow{3}{*}{ 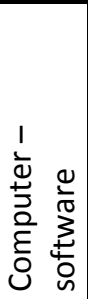 } & Eye Track & $\mathrm{H}$ & $\mathrm{H}$ & $\mathrm{H}$ & - & $M$ & L & - & $M$ & $M$ \\
\hline & Lexion & $M$ & $\mathrm{H}$ & $\mathrm{H}$ & - & - & $\mathrm{L}$ & - & $\mathrm{L}$ & $\mathrm{L}$ \\
\hline & VISIOcoach & $\mathrm{L}$ & $M$ & $\mathrm{M}-\mathrm{H}$ & - & - & $\mathrm{M}-\mathrm{H}$ & - & $M$ & $\mathrm{~L}$ \\
\hline
\end{tabular}

Key: level of ability required to use the intervention (as rated by expert panel): L=Low, M=Medium, $\mathrm{H}=$ High, -=No ability required 
Table 5: Additional scanning training tools identified in Scotland

\begin{tabular}{|l|l|l|l|l|}
\hline $\begin{array}{l}\text { Scanning } \\
\text { Training Tool }\end{array}$ & Modality & Brief Description & Cost & Access Information \\
\hline $\begin{array}{l}\text { DREX } \\
\text { (Durham } \\
\text { Reading \& } \\
\begin{array}{l}\text { Exploration } \\
\text { Training) }\end{array}\end{array}$ & $\begin{array}{l}\text { Computer- } \\
\text { Online } \\
\text { App }\end{array}$ & $\begin{array}{l}\text { Online or app-based training } \\
\text { designed for use at home. It } \\
\text { consists of two types of training: } \\
\text { visual search and reading training, } \\
\text { with the difficulty level increasing } \\
\text { with improvement. }\end{array}$ & Free & $\begin{array}{l}\text { dur.ac.uk/psychology/ } \\
\text { research/drex/ } \\
\text { Also via Apple App } \\
\text { Store and } \\
\text { Google Play. }\end{array}$ \\
\hline Eye-Search & $\begin{array}{l}\text { Computer- } \\
\text { Online }\end{array}$ & $\begin{array}{l}\text { Visual search training that involves } \\
\text { having to "watch a ball roll across } \\
\text { the screen, it jumps unexpectedly } \\
\text { and you have to find it". It has 16 } \\
\text { levels of increasing difficulty. }\end{array}$ & Free & eyesearch.ucl.ac.uk \\
\hline NeuroEyeCoach & $\begin{array}{l}\text { Computer- } \\
\text { Online } \\
\text { hasual search training, where a user } \\
\text { and decide if a particular item is } \\
\text { present amongst distractor items." } \\
\text { The level of difficulty is } \\
\text { automatically adjusted, and it can } \\
\text { be provided alongside restorative } \\
\text { visual therapy. }\end{array}$ & $\begin{array}{l}\text { \$450 } \\
\text { (Around } \\
\text { f350) }\end{array}$ & $\begin{array}{l}\text { novavision.com/neuro } \\
\text { eyecoach/ }\end{array}$ & \\
\hline
\end{tabular}

